\title{
Tests of skeletal muscle function in children
}

\author{
GWILYM P. HOSKING,* ARCHIE YOUNG, $\dagger$ VICTOR DUBOWITZ, AND RICHARD H. T. \\ EDWARDS
}

From the Department of Paediatrics and Neonatal Medicine (Institute of Child Health), Department of Medicine, and the Jerry Lewis Muscle Research Centre, Royal Postgraduate Medical School, Hammersmith Hospital, London

SUMMARY The contractile properties of a large proximal muscle (quadriceps femoris) and a small distal muscle (adductor pollicis) have been measured in normal children and children with neuromuscular disorders. The method of stimulating the quadriceps femoris to contract, previously evaluated in adults, was found to be acceptable to children. In normal children a number of indices of muscle function were found to be similar to those in adults. A small study of the function of the adductor pollicis using supramaximal stimulation of the ulnar nerve was carried out in boys with Duchenne dystrophy. Decreased contractile force and prolonged relaxation times from a tetanic stimulation were noted in both the proximal and distal muscles of the boys with Duchenne dystrophy.

It is logical that an objective assessment of muscle function should be based on measurements of force (Edwards et al., 1977). Although measurements of the voluntary strength of muscles in children can be simply and reliably made (Hosking et al., 1976), there are advantages in being able to assess the function of a muscle independently of volition. Edwards et al. (1977) have described studies of function of a large proximal muscle group, the quadriceps femoris, with electrical stimulation through large surface pad electrodes. Similar studies were made in a small peripheral muscle, the adductor pollicis, using supramaximal stimulation of the ulnar nerve at the wrist. We here describe the use of these techniques in a group of normal children and a group of boys with Duchenne muscular dystrophy. Where possible, comparisons are made between the results obtained by Edwards et al. (1977) in adults.

\section{Methods of study}

\section{Normal children.}

Quadriceps. Measurements were made of the force of maximum voluntary contractions of the quadriceps femoris in 32 normal children between the ages of 4

Received 1 July 1977

Present addresses: *The Hospital for Sick Children, Great Ormond Street, London WC1.

tDepartment of Human Metabolism, University College Hospital Medical School, University Street, London WC1E 6JJ. and 12 years. Stimulated contractions enabled measurements of the 'indices of muscle relaxation' to be made in 16 children, and the 'force-frequency' characteristics in 13.

The subjects were examined either in a muscle testing chair or supine (see below). The chair was adjusted so that the subject's popliteal fossae were at the edge of the seat when the knee was flexed to $90^{\circ}$. The position of the pelvis was fixed with a lap strap. Underneath the seat of the chair an inextensible webbing strap looped around the subject's ankle and passed horizontally backwards to a strain gauge fixed to a rigid but adjustable metal mounting between the back two legs of the chair (Fig. 1). Forces registered by the gauge were recorded, after amplification, with an ultraviolet oscillograph.

For the examination of the supine patient, a strain gauge was mounted on a horizontal bar, itself fixed between two adjustable stands, thus enabling the bar to be raised or lowered. The stands themselves were mounted on a board $(1.5 \times 1.5 \mathrm{~m})$ which was placed on the bed or couch on which the subject lay. A downward-pointing stirrup, screwed directly into the strain gauge, was positioned on the tibial tuberosity while a cylinder placed behind the knee acted as fulcrum (Fig. 2). 5 children had both types of examination performed.

The measurement of voluntary muscle strength was taken as the best of three attempts. The subject was urged to produce the maximum possible effort and to maintain the contraction for $2-3$ seconds. A 


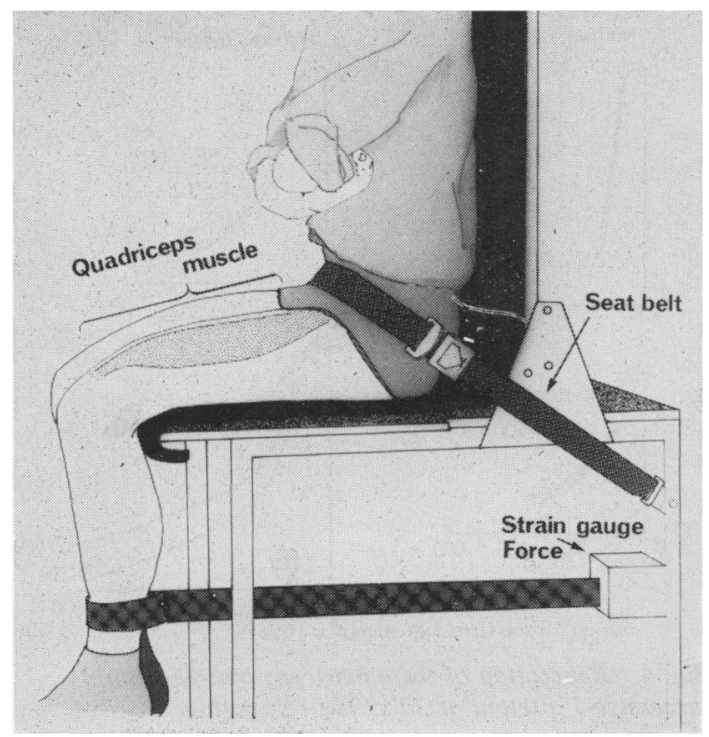

Fig. 1 Muscle testing chair.

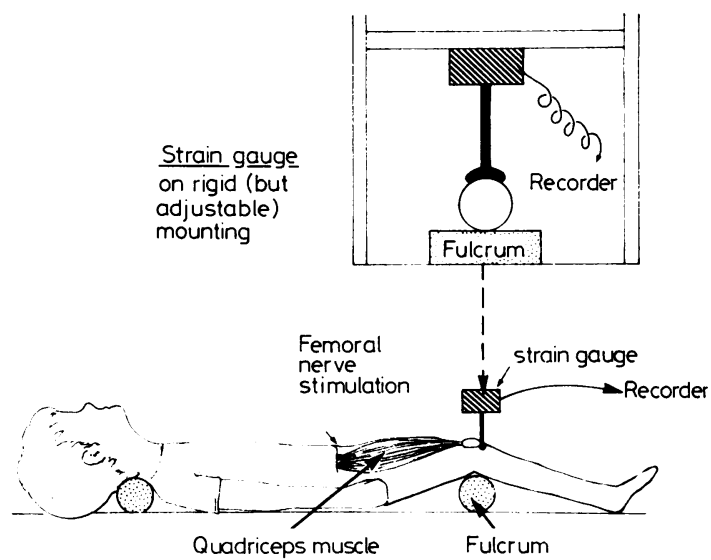

Fig. 2 Strain gauge arrangement for supine examination. Above is shown an enlarged transverse view.

rest of approximately 10-15 seconds was given between each attempt.

The electrical stimulation studies were performed as described by Edwards et al. (1977). Two large saline-soaked pads, serving as electrodes, were bandaged over the vastus lateralis. Subjects varied in size but in general approximately one-third of the anterolateral aspect of the thigh would be covered by these two electrodes. Stimulation was with unidirectional square wave pulses of $50 \mu$ s duration with an output voltage of between 20 and 100 volts. This procedure was similar to the Faradic stimulation technique used by physiotherapists. Small voltages were initially used so that the subject became familiar with the 'feeling' of electrical stimulation of the muscle. Slow increase of the stimulus strength enabled the examiner to determine the minimum voltage necessary to contract approximately $30 \%$ of the quadriceps. The studies were conducted in a warm, well-ventilated room with parental consent and with one parent present. The time taken for the tests did not usually exceed 15 minutes and the procedure was well tolerated.

\section{Boys with Duchenne dystrophy.}

Quadriceps. 12 boys with Duchenne dystrophy of varying severity, ranging in age from 8-17 years, had the examination performed in the muscle testing chair. One boy was examined both in the chair and while supine. In 3 further boys the studies were carried out only in the supine position.

Adductor pollicis. 5 chair-bound teenage boys with Duchenne dystrophy were studied using the method of Edwards et al. (1977). This technique is an adaptation of the techniques of Merton (1954) and Desmedt et al. (1968). A strain gauge was attached to the interphalangeal joint of the left thumb. The hand was secured in supination with the fingers slightly flexed, the thumb abducted, and the first metacarpophalangeal and interphalangeal joints both fully extended. The ulnar nerve was stimulated at the wrist with unidirectional square wave pulses of $50 \mu \mathrm{s}$ duration with an output voltage of between 20 and 60 volts. Stimulus voltage was gradually increased until it was established that the nerve was just supramaximally stimulated.

The temperature of small peripheral muscles varies greatly according to environmental temperature. Before testing the forearm and hand were immersed in water at $45^{\circ} \mathrm{C}$ for 10 minutes. The studies performed were similar to those in the legs and the time taken was approximately 15 minutes for the whole testing procedure.

\section{Results}

\section{Quadriceps.}

Maximum voluntary contractions. Muscle strength is related to the size of an individual and has been shown to correlate with body weight (Hosking et al, . 1976; Edwards et al., 1977). As the quadriceps is a weight-bearing muscle, body weight has been used in this study as the reference variable. The correlation between the maximum voluntary contraction of the quadriceps and body weight in the 32 normal children examined in the chair is shown in Fig. 3, together with the same correlation obtained in adults 


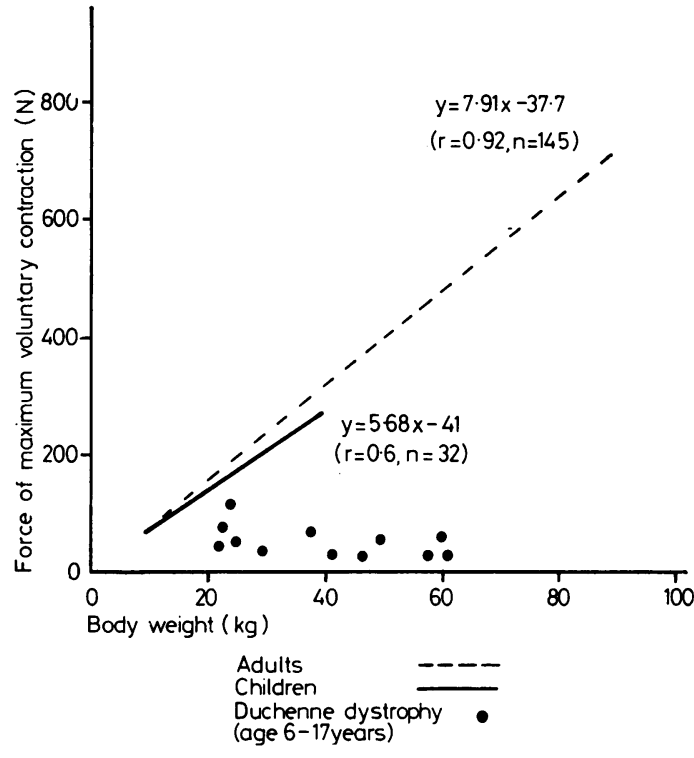

Fig. 3 Strength of quadriceps femoris measured on muscle testing chair. Regression lines for adults, obtained by Edwards et al. (1977), and normal children aged 4-11 years.

by Edwards et al. (1977). In the same figure are the values obtained when 12 boys with Duchenne dystrophy (several of whom were older than the normal children) were tested in the same way. The correlation coefficient obtained for the normal subjects in the study $(0.6)$ is not as high $(0.92)$ as in the study of Edwards $e t$ al. in which the population studied comprised adults and children covering a much wider range of body weights.

\section{Stimulated contractions.}

Relaxation indices. The times from the last stimulus for a $5 \%\left(\mathrm{SF}_{95}\right)$ and $50 \%\left(\mathrm{SF}_{50}\right)$ loss of force after a tetanising stimulation at $30 \mathrm{~Hz}$ were measured (Fig. 4). The results for each individual are expressed as a mean of three successive stimulations.

In Table 1 the two relaxation indices are shown in normal adults (Edwards et al., 1977), normal children, and children with Duchenne dystrophy. From a two-tailed 't-test' it is apparent that the time $\mathbf{S F}_{85}$ is longer in normal children than adults $(P<0.05)$, while those for $\mathrm{SF}_{50}$ are also significantly different. The $\mathbf{S F}_{95}$ and $\mathbf{S F}_{50}$ times in the boys with Duchenne dystrophy were longer than in the normal children $(\mathrm{P}<0.02$ and $\mathrm{P}<0.05$ respectively).

Force-frequency characteristics. The force-frequency characteristics of the quadriceps were studied with

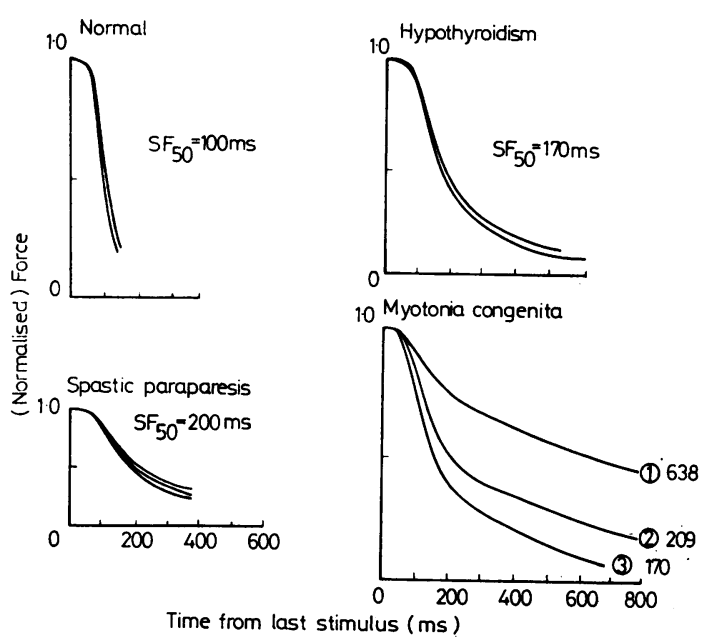

Fig. 4 Relaxation of the quadriceps muscle from 3 successive 1 s tetani at 30/s. The relaxation characteristics in normal muscle and in 3 disease states are illustrated.

Table 1 Comparison of relaxation indices of quadriceps femoris in normal adults, normal children, and boys with Duchenne dystrophy

\begin{tabular}{|c|c|c|c|c|c|c|}
\hline & \multicolumn{2}{|c|}{$\begin{array}{l}\text { Normal } \\
\text { adults } \\
(n=82)\end{array}$} & \multicolumn{2}{|c|}{$\begin{array}{l}\text { Normal } \\
\text { children } \\
(n=16)\end{array}$} & \multicolumn{2}{|c|}{$\begin{array}{l}\text { Boys with } \\
\text { Duchenne } \\
\text { dystrophy } \\
(n=12)\end{array}$} \\
\hline & Mean & $S E M$ & Mean & $S E M$ & Mean & $S E M$ \\
\hline $\begin{array}{l}\mathrm{SF}_{95}(\mathrm{~ms}) \\
\mathrm{SF}_{50}(\mathrm{~ms})\end{array}$ & $\begin{array}{r}60 \cdot 4 \\
104 \cdot 7\end{array}$ & $\begin{array}{l}0.45 \\
1.00\end{array}$ & $\begin{array}{r}57 \cdot 4 \\
114 \cdot 3\end{array}$ & $\begin{array}{l}1.98 \\
2.46\end{array}$ & $\begin{array}{r}67 \cdot 9 \\
128 \cdot 6\end{array}$ & $\begin{array}{l}3.55 \\
7.06\end{array}$ \\
\hline
\end{tabular}

$\mathrm{SF}_{95}$ and $\mathrm{SF}_{50}=$ time from last stimulus for a $5 \%$ and $\mathbf{5 0} \%$ loss of force, respectively

brief periods of stimulation at frequencies of 3-100 Hz. The responses are expressed in relation to the force when stimulated at $50 \mathrm{~Hz}$ (i.e. force tetanus at $50 \mathrm{~Hz}=100 \%$ ) as only minimal force increases were noted at higher stimulation frequencies. The forcefrequency curves in adults (Edwards et al., 1977), normal children, and children with Duchenne dystrophy were similar (Figs. 5 and 6).

An idea of the 'force-frequency' characteristics could be simply obtained by comparing the tension of an incompletely fused tetanus (stimulating at $20 \mathrm{~Hz}$ ) with that obtained when the tetanus was completely fused (stimulating at $50 \mathrm{~Hz}$ ). The ratio obtained is referred to as the tetanus 20/tetanus 50 ratio $\left(\mathrm{TET}_{20} / \mathrm{TET}_{50} \%\right)$. Values for the ratio for normal adults (Edwards et al., 1977), normal children, and boys with Duchenne dystrophy are shown in Table 2. The ratio is higher $(P<0.05)$ in the normal children than the adults, but there was 


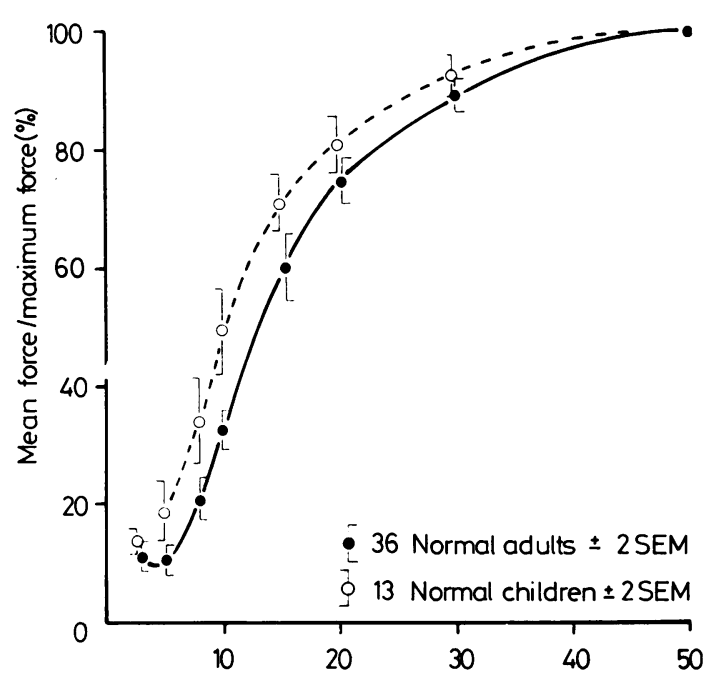

Stimulus frequency $(\mathrm{Hz})$

Fig. 5 Quadriceps femoris. Comparison between force/frequency curves of normal adults and normal children.

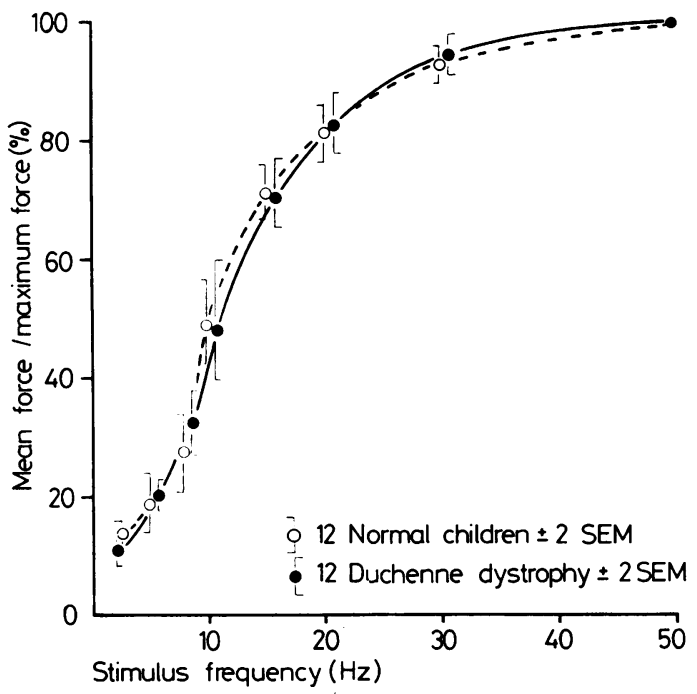

Fig. 6 Quadriceps femoris. Comparison between force/frequency curves of normal children and boys with Duchenne dystrophy.

no significant difference between the normal children and those with Duchenne dystrophy.

Supine examinations were difficult to administer and are therefore not recommended for routine use. The measuring arrangement was not stable and the results lacked consistency on repeated testing when compared to testing on the chair in the same subjects.
Table 2 Comparison of $T E T_{20} / T E T_{50} \%$ of quadriceps femoris in normal adults, normal children, and boys with Duchenne dystrophy

\begin{tabular}{|c|c|c|c|c|c|c|}
\hline & \multicolumn{2}{|c|}{$\begin{array}{l}\text { Normal } \\
\text { adults } \\
(n=78)\end{array}$} & \multicolumn{2}{|c|}{$\begin{array}{l}\text { Normal } \\
\text { children } \\
(n=15)\end{array}$} & \multicolumn{2}{|c|}{$\begin{array}{l}\text { Boys with } \\
\text { Duchenne } \\
\text { dystrophy } \\
(n=12)\end{array}$} \\
\hline & Mean & $S E M$ & Mean & SEM & Mean & $S E M$ \\
\hline TET $_{20} /$ TET $_{50}(\%)$ & $76 \cdot 9$ & $0 \cdot 70$ & $82 \cdot 0$ & $2 \cdot 06$ & $81 \cdot 7$ & $3 \cdot 23$ \\
\hline
\end{tabular}

Nevertheless the studies carried out in a $2 \frac{1}{2}$-year-old girl with a severe mitochondrial myopathy showed that useful information can be obtained with this technique in special circumstances. Supramaximal stimulation (Fig. 7) of the femoral nerve in this child was not painful, probably because of a sensory abnormality.

Adductor pollicis. Edwards et al. (1977) have shown that the responses obtained on stimulating the adductor pollicis were similar to those obtained when the same studies were performed on the quadriceps. The only difference between indices in the two muscles was that the $\mathrm{SF}_{95}$ was shorter in the adductor pollicis.

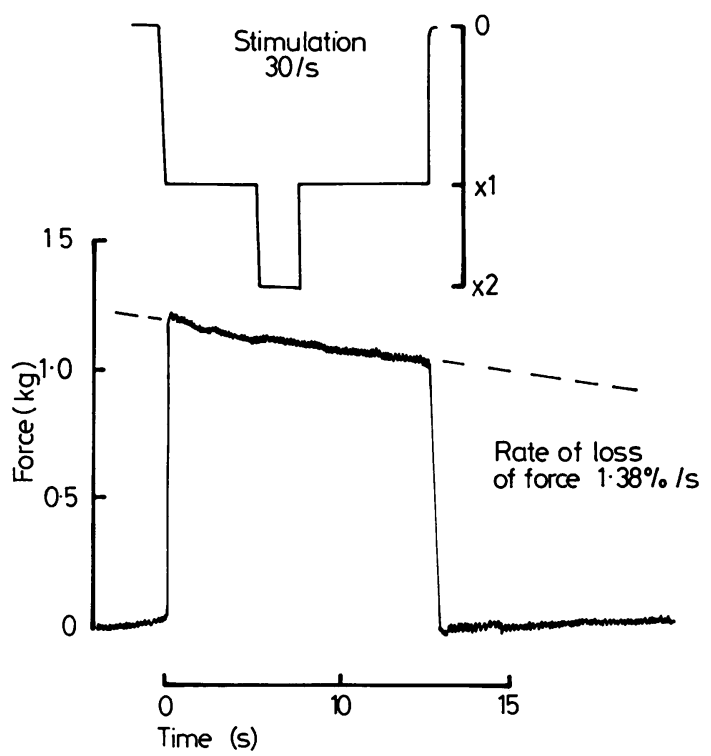

Fig. 7 Force fatigue during contraction of quadriceps with supramaximal stimulation of femoral nerve in a $2 \frac{1}{2}$-year-old girl. Supramaximal stimulation established by showing no increase in force on increasing stimulus voltage. Force registered is the maximum force of patient's muscle. 
In this study the adductor pollicis responses of 5 boys with Duchenne dystrophy are compared with those obtained by Edwards et al. in 10 young adults. Severe weakness was found in the hands of the boys with dystrophy (Fig. 8). Both indices of relaxation $\left(\mathrm{SF}_{95}\right.$ and $\left.\mathrm{SF}_{50}\right)$ were prolonged in these boys $\left(\mathrm{P}<0.001\right.$ in both cases), while the $\mathrm{TET}_{20} / \mathrm{TET}_{50} \%$ was lower than in the adults $(P<0.005)$ (Table 3$)$. The force frequency curves in the two groups were similar.

Table 3 Comparison of the responses to electrical stimulation of the adductor pollicis in normal adults and teenage boys with Duchenne dystrophy

\begin{tabular}{|c|c|c|c|c|}
\hline & \multicolumn{2}{|c|}{$\begin{array}{l}\text { Normal adults } \\
(n=10)\end{array}$} & \multicolumn{2}{|c|}{$\begin{array}{l}\text { Boys with } \\
\text { Duchenne dystrophy } \\
(n=5)\end{array}$} \\
\hline & Mean & $S E M$ & Mean & $S E M$ \\
\hline $\begin{array}{l}\mathrm{SF}_{95} \text { (ms) } \\
\mathrm{SF}_{50}(\mathrm{~ms}) \\
\mathrm{TET}_{\mathbf{2 0}} / \mathrm{TET}_{50}(\%)\end{array}$ & $\begin{array}{l}51 \cdot 2 \\
95 \cdot 8 \\
73 \cdot 1\end{array}$ & $\begin{array}{l}1 \cdot 6 \\
3 \cdot 4 \\
2 \cdot 8\end{array}$ & $\begin{array}{r}73 \cdot 4 \\
159 \cdot 3 \\
80 \cdot 7\end{array}$ & $\begin{array}{l}1 \cdot 7 \\
3 \cdot 0 \\
0 \cdot 94\end{array}$ \\
\hline
\end{tabular}

\section{Discussion}

Most diseases of muscle have predominantly proximal distribution. The majority of previous physiological studies of muscle function have been on small peripheral muscles in which the motor nerves have been accessible to supramaximal stimulation (Mer-

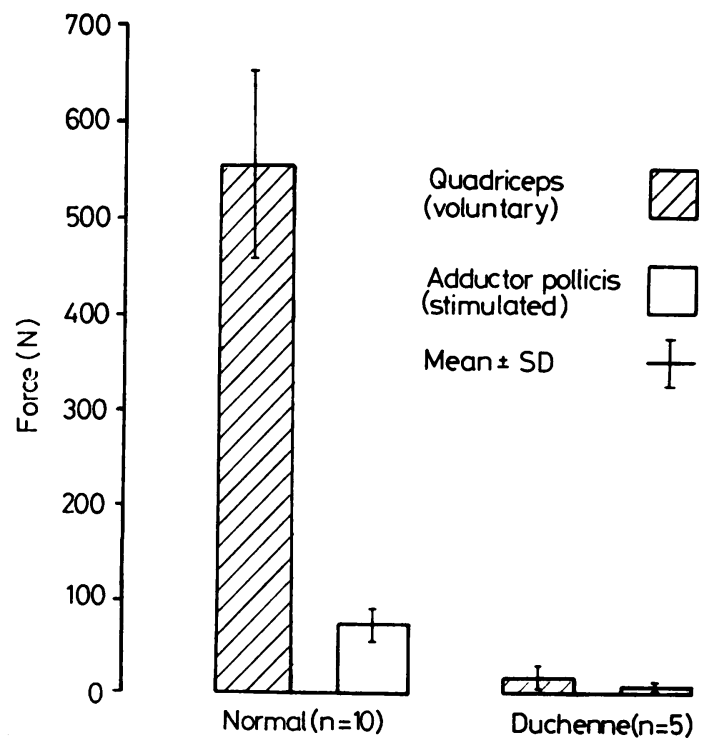

Fig. 8 Strength of adductor pollicis and quadriceps femoris in normal adults and in boys with Duchenne dystrophy. ton, 1954; Desmedt et al., 1968; McComas and Thomas, 1968; Sica and McComas, 1971; Burke et al., 1974). Such a stimulation of the femoral nerve produces a powerful contraction of the quadriceps femoris which is normally both uncomfortable and not without risk of injury. The technique of Edwàrds et al. (1973), exploiting maximal stimulation of a group of local intramuscular branches of the femoral nerve, is not accompanied by significant discomfort or risk and is capable of quantitating several indices of function (Edwards et al., 1977). This study has examined the feasibility in children following the development of the techniques of stimulation in adults. The results show that normal children have a number of indices of function which although not identical are very similar to those of adults.

The maximum contractile force of the quadriceps muscle has been taken as the force of a maximum voluntary contraction because supramaximal (tetanic) femoral nerve stimulation is so often painful. In this study the force of the stronger leg has been recorded. As in the adults the second and third of the three contractions gave similar results. A fourth contraction was performed if there was a marked difference between these values.

Maximum voluntary contractions of the adductor pollicis in the boys with muscular dystrophy were difficult because of the contractures involving the elbow joints that these boys had. For this reason the maximum contractile force of the adductor pollicis was taken as its maximum stimulated contraction.

Examination of the speed of relaxation of a muscle from a contraction has previously been applied to studies of the tendon reflexes and brief electrically stimulated contractions (Desmedt et al., 1968). Since most voluntary muscle activity involves sustained contractions, Edwards et al. (1977) have concentrated on examining the rate of relaxation from tetani produced by stimulation at $30 \mathrm{~Hz}$. Higher frequencies often failed to produce a satisfactory force 'plateau' due to impaired neuromuscular transmission or other forms of fatigue.

Studies of animal muscular dystrophy have shown that not only is there a decreased tension output from dystrophic muscle and decreased fatigability but, in spite of normal contraction times, prolonged relaxation times from twitch and tetanic contractions (Sandow and Brust, 1958; Neerunjun et al., 1976).

In this study of boys with Duchenne muscular dystrophy slow relaxation after tetanic stimulations was noted in both the quadriceps femoris and the adductor pollicis. There was, however, a wide scatter of results in the study of the quadriceps, reflecting the difficulties of studying this muscle in the advanced stages of the disease. This in itself suggests that the adductor pollicis may be a more suitable muscle to 
study in advanced stages of Duchenne dystrophy. Fatigability studies were not carried out because this would have caused discomfort.

The similarity between the force-frequency curves in the normal children and those with muscular dystrophy was a definite but somewhat surprising finding. Moulds et al. (1977) have shown that 'slowing' of a muscle produces a shift of the forcefrequency curve to the left; however, any impairment in electromechanical coupling, as indicated by the data of Desmedt et al. (1968), would tend to shift the curve to the right. This phenomenon is currently under investigation but it is too early to give a precise explanation for the present observations in Duchenne dystrophy.

Study of the children while supine was technically difficult but during the course of the work it was realised that quite severely weakened children could be examined on the muscle testing chair. Performing tests such as those described in children requires patience and positive efforts to allay anxiety. Having done this, children did not find the process unpleasant and good quality records were obtained. In very few instances did the tests on the quadriceps femoris or the adductor pollicis take more than 15 minutes and in most it was less than 10.

We are grateful for geneous financial support from the Sir William Coxen Trust, the Muscular Dystrophy Group of Great Britain, and the Wellcome Trust; and for help from Dr D. N. Lawson and Mr R. J. S. Reynolds of Queen Mary's Hospital for Children, Carshalton.

\section{References}

Burke, D., Skuse, N. F., and Lethlean, A. K. (1974). Isometric contractions of the abductor digiti minimi muscle in man.
Journal of Neurology, Neurosurgery and Psychiatry, 37, 825-834.

Desmedt, J. E., Emeryk, B., Renoirte, P., and Hainaut, L. (1968). Disorder of muscle contraction processes in sexlinked (Duchenne) muscular dystrophy with correlative electromyographic study of myopathic involvement in small hand muscles. American Journal of Medicine, 45, 853-872.

Edwards, R. H. T., Hill, D. K., and McDonnell, M. (1973). Metabolic heat production and relaxation rate of electrically stimulated contractions of the quadriceps muscle in man. Journal of Physiology, 231, 81 P-83P.

Edwards, R. H. T., Young, A., Hosking, G. P., and Jones, D. A. (1977). Human skeletal muscle function: description of tests and normal values. Clinical Science and Molecular Medicine, 52, 283-290.

Hosking, G. P., Bhat, U. S., Dubowitz, V., and Edwards, R. H. T. (1976). Measurements of muscle strength and performance in children with normal and diseased muscle. Archives of Disease in Childhood, 51, 957-963.

McComas, A. J., and Thomas, H. L. (1968). Fast and slow twitch muscles in man. Journal of Neurological Sciences, 7, 301-307.

Merton, P. A. (1954). Voluntary strength and fatigue. Journal of Physiology, 123, 553-564.

Moulds, R. W. F., Young, A., Jones, D. A., and Edwards, R. H. T. (1977). A study of the contractility, biochemistry, and morphology of an isolated preparation of human skeletal muscle. Clinical Science and Molecular Medicine, 52, 291-297.

Neerunjun, J. S., Jones, D. A., and Dubowitz, V. (1976). Functional properties of muscles transplanted between normal and dystrophic mice. Experimental Neurology, 52, 556-564.

Sandow, A., and Brust, M. (1958). Contractility of dystrophic mouse muscle. American Journal of Physiology, 194, 557-563.

Sica, R. E. P., and McComas, A. J. (1971). Fast and slow twitch units in human muscle. Journal of Neurology, Neurosurgery and Psychiatry, 34, 113-120.

Correspondence to Professor R. H. T. Edwards, Department of Human Metabolism, University College Hospital Medical School, University Street, London WC1E 6JJ. 